\title{
AN INVESTIGATION ON THE EFFECTS OF PROCESSING ON THE FIBER LENGTH AND MECHANICAL PROPERTIES OF COMPRESSSION MOULDED GLASS FIBER REINFORCED POLYPROPYLENE COMPOSITES
}

A.M. Yaacob', S.M. Sapuan ${ }^{2}$, E.S. Zainudin', M. Ahmad'and K. Z. M. Dahlan ${ }^{2}$ Advaneed Material Laboratory, Institute of Advaneed Technology, Universiti Putra Malaysia, 43400 Serdang, Selangor, Malaysia

${ }^{2}$ Department of Mechanical and Manufacturing Engineering Universiti Putra Malaysia, 43400 Serdang, Selangor, Malaysia.

Radiation Processing Technology Division, Malaysian Institute for Nuclear Technology Research (MINT), Bangi, 43000 Kajang, Selangor, Malaysia

(Roceived: 29 March, 2005)

\section{ABSTRACT}

A study on tensile strength and modulus glass fibre reintorced polypropylene composite is presented in this paper. The composites are compounded in a singie screw extruder and the samples based on the polypropylene matrix are prepared using compression moulding process. The study of critical fibre length is crucial in order to ensure the mechanical properties obtained for composites and the values are superior to that of virgin polymer. However, in this study, the resuits of tensile strength show decreasing trend compared to virgin polypropylene as the fibre content is increased. Low mechanical properties are obviously related to the absence of interface adhesion between fibre and polymer. The results of tensile modufi show increasing trend but the maximum values of tensile moduli are much lower to the typical value of glass fibre composites. This is possibly caused by fibre breakage below the critical length and the values of tensile moduli obtained are actually the value of virgin polypropylene.

\section{INTRODUCTION}

In composite industry, fibre properties are determined by the fibre manufacturing process. Many composites are not reinforced by continuous fibers but by short fibers because the manufacturing processes for continuous fiber reinforced composites tend to be slow, inflexible and more expensive than short fiber reinforcement (Zainuddin et al., 2002). In short fibre composite produced using compression moulding the main problem normally encountered is shortening of fibre length. The reduction in fibre length is partly due to the requirements of the processing technique, but some processes, which involve mechanical shearing and mixing actions also promote considerable fibre breakage (Matthews and Rawlings, 1994). In compression moulding process the preparation of samples need to be done in screw extruder. In the extrusion process, it normally contains general shear as well as extreme shear where screw/barrel almost touches each other. In some regions there might be extension to those mentioned earlier as 
well such as the phenomenon of fibre rotation. Fibres rotate in the melt is causing collisions and locking and finally breakage. A fibre which is not aligned along a vector of constant velocity will experience a tension and this is possibly the main reason for fibre breakage.

During processing fiber breakage occurs due to the factors such as fiber-fiber interaction, converging flow, flow around sharp corners, spatial hindrance in the sprue, gate or mold and the presence of a partially molten phase with a solid phase (Jozseff, 2000). In its simplest terms the extrusion technique consists of forcing a polymer in liquid form under pressure through a die to produce a continuous section or profile (Stevens, 1985). It is generally understood that structural modification and degradation occur inside the barrel of the extruder due to the segregation of parts of the screw in the barrel where the extruder required to do mechanical and shearing on the polymer melt. This action reduces the molecular weight spread and improves product properties (Stevens, 1985). According to Gibson (1995), the maximum length that can be retained using extrusion-compounding method for polypropylene/glass fibre appears to be limited to values substantially below $1 \mathrm{~mm}$. Therefore, it is essential when processing short glass fiber PP composites to minimize all possible sources of fiber breakage.

The objective of this study generally is to utilize the principles of single screw extrusion processes using polypropylene (PP)/glass fibre (GF) composites and specifically to study the effect of processing on the fiber length. This factor must be taken into account without fail in order to increase the objectivity of control. The reduction in fiber length is partly due to the processing techniques which involve mechanical shearing and mixing actions. These promote considerable amount of fiber breakage. Fiber breakage occurs drastically during mass production and reduces the fiber length by the shearing action of the screw and in this case the extruder. It causes the properties of the reinforcement to decrease.

The mechanical properties such as tensile property of PP/GF composites that are important in melt processing are discussed in this paper. In the present work, polypropylene (PP) composites reinforced with short glass fiber were prepared by extrusion compounding technique. The tensile properties of these composites were investigated taking into consideration the combined effects of fiber fractions (e.g. $5 \%$ wt, $10 \%$ wt and $15 \%$ wt of glass fiber) and mean fiber lengths of $6 \mathrm{~mm}$ and $12 \mathrm{~mm}$. Three batches of compounded polypropylene with Melt Flow Index of $24 \mathrm{~g} / 10$ 
min were reinforced with $5 \%, 10 \%$ and $15 \%$ by weight of glass fibers. The main purpose here is to study the effect of single screw extruder compounding on fiber length and mechanical properties of prepared samples. The earlier work of the authors studied the processing effects on fibre length based on injectionmolded samples (Yaacob et al., 2003).

It is very difficult to measure the length of short fiber prior to its processing and if it is below the critical length, the fiber cannot effectively reinforce a matrix. When a fiber is too short, stress cannot be transferred from other fibers, and then the fiber is not an effective load-bearing element in the composite parts. Although the fibers add mass to the composites parts and increases the parts weight it is not capable of carrying its share of the load. The 'un-reinforced' fibers with regards to its low fiber length somehow created a defect by introducing an inclusion such as void to the entire matrix and eventually reduce the potential strength for the entire parts.

In this paper the mechanical properties relating to effects of processing using extruder method for PP/GF composites is expiained focusing on certain factors that may affect the mechanical results such as screw design and percentage of glass used which are relevant to melt extrusion processing. During processing fibers tend to slide past one another and break when shear involves in reducing the crosssectional area and length. The preparation of samples produces friction and high shear forces among fibers that eventually break the fiber into pieces and below their critical length. Damage fibers create a stress concentration point in a finish part. Reinforced composites that encountered fiber breakage inside its matrix cannot be used to their maximum stress carrying capability and lead to composites with poor performance with regard to its strength.

\section{EXPERIMENTAL}

\section{Materials}

The polypropylene used was PP stock, grade $710 \mathrm{G}$ from Polypropylene Malaysia with melt flow index of $24 \mathrm{gram} / 10 \mathrm{~min}$ in pellet form. E type glass fiber was used with two different lengths namely 6 and $12 \mathrm{~mm}$. It was supplied by Team Pacific Sdn. Bhd., Petaling Jaya, Malaysia. Basically Electrical or E-glass composed of $55 \%$ silica oxide, $20 \%$ calcium oxide, $15 \%$ aluminum oxide and $10 \%$ boron oxide (standards grade of glass used in fiber glass and has a tensile strength of about $3.45 \mathrm{GPa}$. The specific gravity of glass fibre was $2.59 \mathrm{~g} / \mathrm{cm}^{3}$. The 
minimum and maximum water absorption values were $0.2 \%$ and $0.4 \%$ respectively. The giass filament diameter was $14.5 \mu \mathrm{m}$, the fibre was in the form of chopped strands and the glass type was E or Electrical glass.

\section{Preparation of composites samples}

Material used was first oven dried at $60^{\circ} \mathrm{C}$ for 24 hours before processing. Sample was prepared by mixing approximately $5 \%, 10 \%$ and $15 \%$ by weight of glass fiber into polypropylene resins by using a single screw extruder type Brabender 19/25 D, single screw 1:1 using side feeding method. Overall length for the screw is approximately 70 $\mathrm{mm}$, shaft gap is $15 \mathrm{~mm}$, screw diameter is $19 \mathrm{~mm}$ and the grove thickness is $3 \mathrm{~mm}$. Processing temperatures for single screw extruder were set to $180^{\circ} \mathrm{C}, 190^{\circ} \mathrm{C}, 195^{\circ} \mathrm{C}$ and $200^{\circ} \mathrm{C}$. Inside the die, the compound is subjected to a constant pressure proposed by the manufacturers for polypropylene and glass fibre. The orientation of the fibre when the composite leaves the extruder is random observed by naked eyes. The compounded extrudates were immediately quenched in water. Then the extruded fibre bundles were cut to approximately 3-4 inches and dried in an air circulating oven for another 24 hours at $60^{\circ} \mathrm{C}$.

Samples were prepared using a $15 \mathrm{~cm} \times 15 \mathrm{~cm}$ moulded components. The mould was preheated to $200^{\circ} \mathrm{C}$ for approximately 4 minutes with 3 seconds of air ventilation. The samples were then cooled in a second cold press for 3 minutes. Pressure was set at $1200 \mathrm{~kg} / \mathrm{cm}^{2}$ during pressing for each batch of samples. Weight average for each sample is approximately 40 gram per run. The sheets were cut according to ASTM 638 (Type 5) for tensile specimen preparation.

Fiber length measurement

Damage of the fibers is assumed to have already occurred after flowing through nozzle of the extruder machine during its processing. To measure the actual fiber length, the method used was to burn the matrix at $550^{\circ} \mathrm{C}$ for 15 minutes in a furnace leaving behind fiber ash. Residual was then dispersed in water. Approximately 10 fibres were chosen randomly and transferred to a glass slide. Images were then taken using light microscope with 40 times magnification to determine the length. The average length of fibres is then obtained. 


\section{Tensile test}

The tensile properties of specimens were determined using 5 samples for each composite with an Instron testing machine at a constant crossspeed of $5 \mathrm{~mm} / \mathrm{min}$.

\section{RESULTS AND DISCUSSION}

\section{Fibre length results}

Normaily, it is customary to produce a curve for the number of fibres versus the length of the fibres after matrix being burnt in order to obtain the average length and comparing it with that of. $I_{0}$. However, in this study such measurement cannot be carried out because the task is very tedious and time consuming. It cannot be carried out within limited time.

According to Matthew and Rawlings (1994), the mean value for the critical fibre length $\left(I_{\sigma}\right)$ for polypropylene/giass composite is $1.8 \times 10^{3}$ $\mu \mathrm{m}$. It is important to consider length of fibre to be longer than the critical length. Generally, when the length of the fibre in the samples is lower than $I_{\sigma}$, then there would be a reduction in both strength and mechanical properties of the composite. The concept of critical fibre length was determined over which the stress transfer allows the fibre to be stressed to its maximum, has been used to predict the strength of the composites (De and White, 1996, and Powell and Housz, 1998).

Figure 1 shows the results of final fibre length at various initial lengths and fibre contents. It is observed that at the same percentage of the glass fibre content in the PP matrix and the two initial lengths of fibres, the final fibre length shows increasing trend. At $5 \%$ of fibre content, the final fibre length for the sample with the initial length of 6 $\mathrm{mm}$ is $0.5 \mathrm{~mm}$ and for $12 \mathrm{~mm}$ is $1.4 \mathrm{~mm}$. For $10 \%$ of fibre content, the final fibre length for the sample with the initial length of $6 \mathrm{~mm}$ is $0.8 \mathrm{~mm}$ and for $12 \mathrm{~mm}$ is $1.8 \mathrm{~mm}$. Finally for $15 \%$ of fibre content, the final fibre length for the sample with the initial length of $6 \mathrm{~mm}$ is $1.0 \mathrm{~mm}$ and for $12 \mathrm{~mm}$ is also $1.8 \mathrm{~mm}$. It shows that as the fibre content increases the the final fibre length gives the higher values. The fiber was damaged during compounding and it shows that fibres with the length less than 2 $\mathrm{mm}$ were left inside samples. The initial fiber lengths were $6 \mathrm{~mm}$ and 12 $\mathrm{mm}$, and therefore the average length was reduced by almost $80 \%$. By foliowing the value of critical fibre length $\left(l_{c}\right)$ of $1.8 \mathrm{~mm}$, given by Matthews and Rawlings (1994), only the composites with initial fibre length $12 \mathrm{~mm}$ with fibre contents of 10 and $15 \%$ have the final length exactly the same with the critical length. 


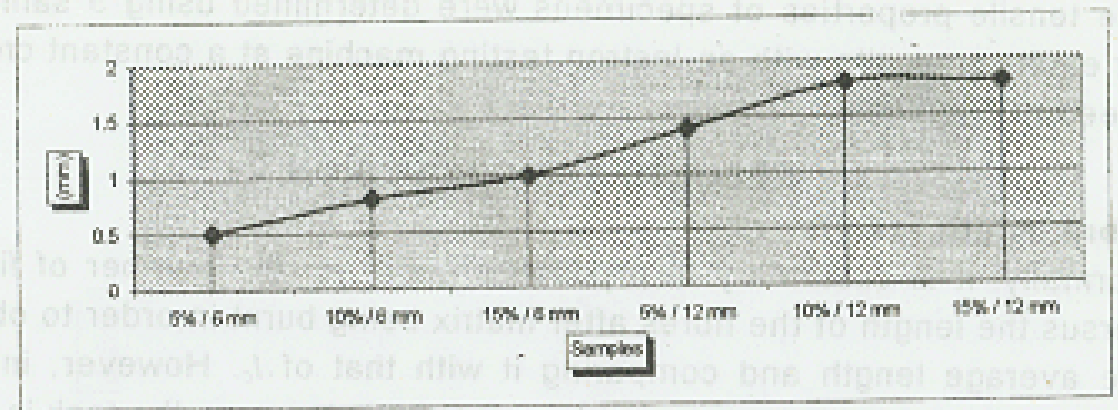

Figures 1: Average fibre length results

\section{Tensile properties}

Figures 2 and 3 show the tensile strength results for polypropylene/glass composites at initial length of 6 and $12 \mathrm{~mm}$ respectively. In both cases, as the fibre content increases, the values of strength decrease even much lower than the virgin polypropylene. The reason is that the there is no adhesion between polypropylene and glass fibre, probably due to the difference in polarity between polypropylene and the hydroxyl groups on the fibre surface. A silica oxide glass like E-glass has polar hydroxyl groups and it is only compatible with polymers having polar groups.

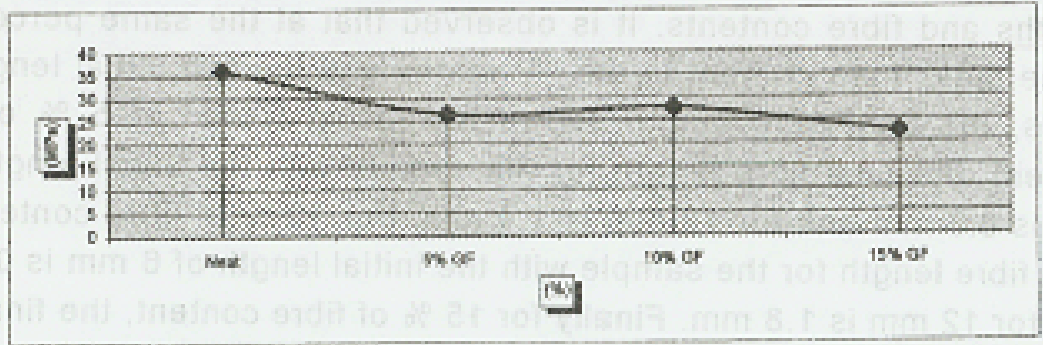

Figure 2: Tensile strength results for $6 \mathrm{~mm}$ fiber length using compression molding technique

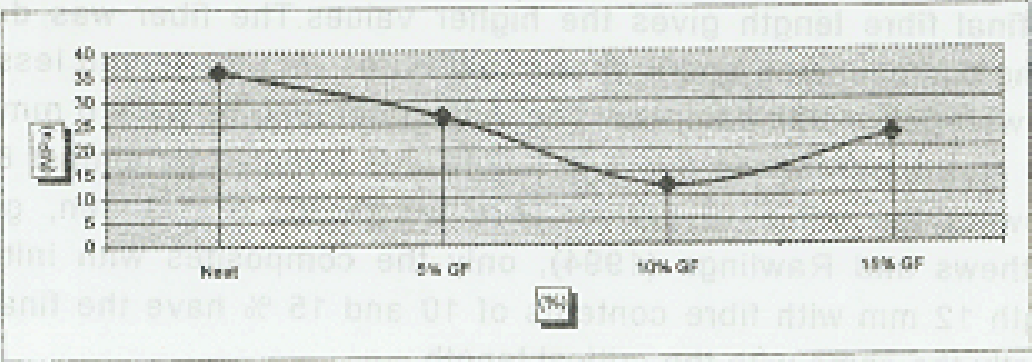

Figure 3: Tensile strength results for $12 \mathrm{~mm}$ fber length using compression molding technique 
Polypropylene has extremely. low polarity, hence the adhesion was almost zero. The reduction in properties more or less corresponds to the reduction of matrix material. this means that no load is transferred to the fibres. Fibre surface treatment is required to overcome this problem such as to treat the glass fibre in a very special way like with a maleate. These results are completely contradicted to the results of Thomason et af. (1996) because in their study, as the fibre contents increase, the tensile properties improved. It is believed that they have carried out proper interfacial adhesion study by treating the glass fibre with suitable chemicals.

Another reason for the decrease in mechanical properties was observed probably with respect to the decreasing of the fiber length. Generaliy fibre plays a major role in concentrating the stress in the matrix hence creating a stress concentration area inside the matrix phase. Studies on failure mechanism shows that under loading of tensile stress, the cracks start at the fibre ends and propagate along the fibre- matrix interface or cross through the matrix and finally failure occurs. It should be noted fibres used in this study is glass fibre and it is brittle and thus breakage easily took place during processing.

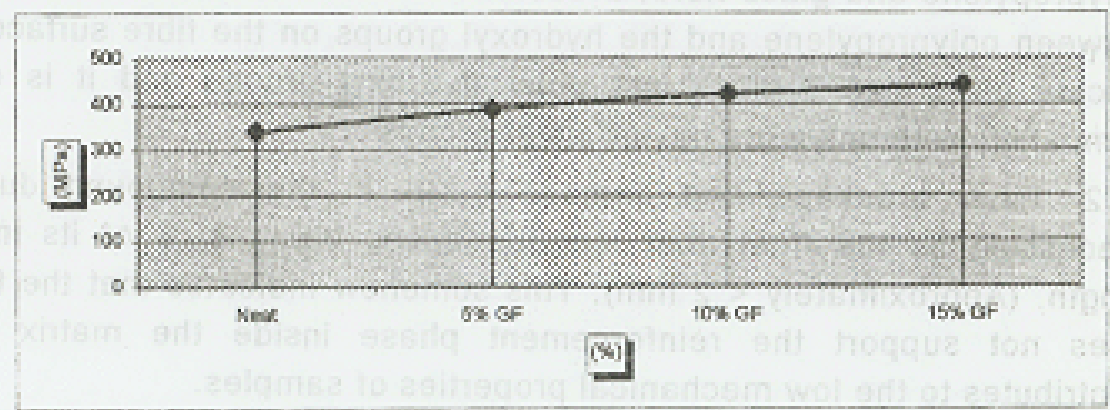

Figure 4: Tersile modulus for $6 \mathrm{~mm}$ fiber length using compression molding technique

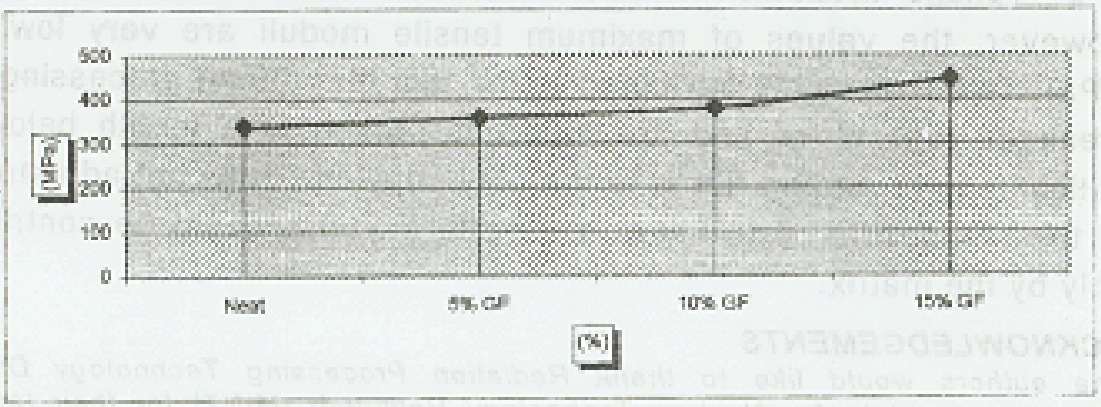

Figure 5: Tensile modulus for $12 \mathrm{~mm}$ fber length using compression molding technique 
Figures 4 and 5 show the tensile modulus results for polypropyiene/glass composites at initial length of 6 and $12 \mathrm{~mm}$ respectively. For tensile modulus, as the fibre content increases, the tensile modulus results increase. However, the maximum values for tensile modulus for both initial fibre lengths (6 and $12 \mathrm{~mm}$ ) are quite low (approximately $450 \mathrm{MPa}$ for both cases). The typical value of tensile modulus for glass fibre composite is $3000 \mathrm{MPa}$. This is possibly because during processing fibre breakage took place and the fires has broken to below the critica! length. Adding fibres to the polypropylene does not add strength to the composites. The value of tensile modulus could be contributed only by the matrix.

\section{CONCLUSIONS}

In spite of the unfavorable reinforced system in polymer taken from compression moulding compounds, reproducible data have been obtained from this investigation and they are concluded as follows:

1- The results of tensile strength indicate that as the fibre content increases, the values of strength decrease even much lower than the virgin polypropylene. The reason is that there is no adhesion between polypropylene and glass fibre, associated with the difference in polarity between polypropylene and the hydroxyl groups on the fibre surface. A silicate glass like E-glass has polar hydroxyl groups and it is only compatible with polymers having polar groups.

2- Fiber breakage and damage occur in the compound during processing as the final fiber length reduces up to $80 \%$ of its initial length. (Approximately $<2 \mathrm{~mm}$ ). This somehow indicates that the fiber does not support the reinforcement phase inside the matrix and contributes to the low mechanical properties of samples.

3- Tensile modulus increases with the increase of fiber weight. However, the values of maximum tensile moduli are very low (450 MPa). This is possibly attributed to the fact that during processing fibre breakage took place and the fires has broken to a length below the critical length. Adding fibres to the polypropylene does not add strength to the composites. The value of tensile moduius could be contributed only by the matrix.

\section{ACKNOWLEDGEMENTS}

The authors would like to thank Rediation Procossing Technology Division. Maiaysian institute for Nuclear Technology Research (MINT) for their technical support on this projeot and Polypropyiene (M). Gebeng. Kuantan, Malaysia for material support. This project is partly supported by Ministry of Science, 
Technology and innovations, Malaysia under the IRPA mechanism grant vote 54068 .

\section{REFERENCES}

De, S.K. and White, J.R. (1996), Short Fibre - Polymer Composites, Woodhead Publishing Limited, Cambridge.

Gibson, A.G. (1995). Processing and Properties of Reinforced Polypropylenes. In Polypropylene: Structure, Blends and Composites: Vol. 3 Composites, (ed. J. Karger-Koesis), London, Chapman and Hall.

Jozseff, K.K. (2000). Reinforced Polymer Blends. In Polymer Blends: Volume 2: Performance. (eds, D.R. Paul and C.B. Bucknall), pp 395 - 428, London: John Wiley and Sons inc.

Matthews, F.L. and Rawlings, R.D. (1994)., Composite Materials: Engineering and Soienov, Chapman \& Hall, London.

Powell, P.C. and Housz, A.J.I. (1998), Engineers with Polymers, Stanley Thornes (Publishers) Ltd., UK.

Stevens M.J. (1985). Extruder Principles and Operation, Oxford, Elsevier Applied Science Publishers Ltd.

Thomason, J.L., Viug, M.A., Sehipper, G. and Krikot, H.G. L.T. (1996), The influence of fibre length and concentration on the properties of glass fibre reinforced polypropylene: part 3, strength and strain at failure., Composites Part A, vol. 27A, pp. 1075-1085.

Yaacob, A.M., Ahmad, M. Dahlan, K.Z.M. and S.M. Sapuan (2003). Preliminary studies on short fiber reinforcement injection molded thermoplastic composites. Propoedings of Conference on Advanced Materials, Advanoed Technology Congress 2003, Putrajays, Solangor, Malaysia, 20 - 21th May 2003, pp, 1-5.

Zainuddin, E.S., Sapuan, S.M, Sulaiman, S, and Ahmad, M.M.H.M. (2002), Fibre orientation of short fibre reinforced injection moulded thermoplastic composites: a review, Journal of Injection Moulding Technology, 6, no. 1, pp. 1-10. 